\title{
ROADWAY STABILITY EVALUATION ON THE BASIS OF MODERN MONITORING OF DISPLACEMENT
}

\author{
TADEUSZ MAJCHERCZYK, ZBIGNIEW NIEDBALSKI, ARTUR ULASZEK \\ AGH University of Science and Technology, Department of Geomechanics, \\ Civil Engineering and Geotechnics, Kraków, Poland. \\ e-mail: tmajcher@agh.edu.pl
}

\begin{abstract}
The paper presents the application of a 3D laser measurement technology in a modern monitoring of roadways. The authors analyze the possibility of using a three-dimensional scanning measurement of longwall working dimensions. The measurement results are presented in the form of a cloud of points obtained from a 3D laser scanning. The paper also presents a comparison of the results obtained from the convergence of traditionally-made measurements with the measurements derived from the threedimensional scanning and discusses possible methods of comparing different point clouds.
\end{abstract}

Key words: roadways, monitoring, convergence

\section{INTRODUCTION}

Evaluation of roadway stability in underground mines constitutes an important part of mining engineers' work. Numerous types of geodesic equipment, technological solutions and methods of gathering data have been hitherto tested in mining in order to evaluate roadway stability on the basis of changes in their cross sections. As a result of a massive technological development, the application of a laser scanner became more common in preparing a threedimensional models of roadways, which further allowed for utilizing the obtained coordinates in numerical models representing the phenomena occurring in rock mass, determining the support loading, as well as predicting possible undesired phenomena in the analyzed strata.

The paper presents modern state-of-the-art solutions in monitoring the dimensions of roadways. The fulfillment of measurement tasks requires specific measuring instruments. Nowadays electronic distance meters (EDM) are commonly used, as well as electronic tachymeters, matching theodolite with EDM technology in one device operated with an in-built dedicated geodesic application [3].

While gathering data of coordinates pertaining to individual points $(X, Y, Z)$, the tachymeter utilizes codes of the elements to identify the particular points measured. The data are transformed and corrected with the use of the software in order to obtain the results of three-dimensional models of terrain or objects.

Although tachymeters have been successfully used as measurement instruments in mining for a long time, nowadays state-of-the-art 3D laser scanners seem to gain more popularity. The scanners, functioning similarly to mirror-less measurement stations, gather $X, Y$ and $Z$ coordinates from the entire surrounding using one device for generating a high-resolution point cloud.

3D laser scanning technology is applied in order to upgrade the efficiency and precision of measurement, to increase the security, as well as to limit the necessary time of measurement in comparison to the traditional methods. Outstanding accuracy is one of the main benefits of applying the new measurement technology. Furthermore, 3D laser scanners do not require specifying the location since the gathered points refer spatially to the device. The systems with the measurement of phase shift emit a laser beam with a specified frequency ("emitted light"). Part of the beam reflects back to the system ("returning light"). The phase of the "returning light" is compared to the phase of the specified frequency, whereas the difference between the two peak values constitutes the "phase shift". The scanner with the phase shift is currently regarded as one of the most efficient and precise laser scanning instruments, since it allows for a rapid data collection and gen- 
eration of high-resolution scans. In combination with the measurements performed at specified intervals or at every change of the state of the measuring object geometry, laser scanning allows the users to perform a spatial scan of the field of vision (3D) within a given area [1]. The obtained cloud of millions of points can be used, among others, for the representation of the terrain and to obtain a highly precise approximation of its appearance. An important advantage of measurement systems using a 3D scanner in mining excavations is the possibility to reduce the time of measurements and the number of people performing the measurement [5]. Laser scanning allows for the so-called virtual returns to a certain location, which helps to limit the number of additional visits to the measurement station. Utilizing the $3 \mathrm{D}$ data gathered with the use of a laser scanner can generate detailed results of the actual dimensions of mining workings [6], determine the convergence, execute the measurements of displacement and help construct the numerical models for the prediction of changes in the analyzed rock mass [2].

The primary benefit of the application of scanning technology in mining is its visualization potential: from the simplest isometric projections (providing an overall view of the spatial location of the roadways, shafts, as well as the equipment and objects on the surface of the mine) to the highly precise surveys (giving the possibility of generating cross sections, calculating the volume or monitoring the deformation).

\section{RESEARCH STATION AND MEASUREMENT EQUIPMENT}

Laser monitoring embraced the ventilation bottom gate $\mathrm{K}-2$, executed in the yielding arch support with the use of mechanical lining in the form of bags filled with a cement binder and with the use of traditional lining in the form of barren rock placed behind the support. The bottom gate $\mathrm{K}-2$ is situated in the seam $362 / 1$ at a depth of $986 \mathrm{~m}$ (Fig. 1).

The roadway was used as a kind of research laboratory as its support had been executed in two different ways in its two sections, i.e., using the technology with the mechanical lining and with the traditional hand-made lining. Almost 600 meters of the roadway were reinforced with the mechanical lining in the form of bags with a mineral-cement binder placed on the arch of the roof of the yielding arch support (Fig. 2a), whereas the remaining 400 meters were executed using traditional technology with the hand-made lining (Fig. 2b).

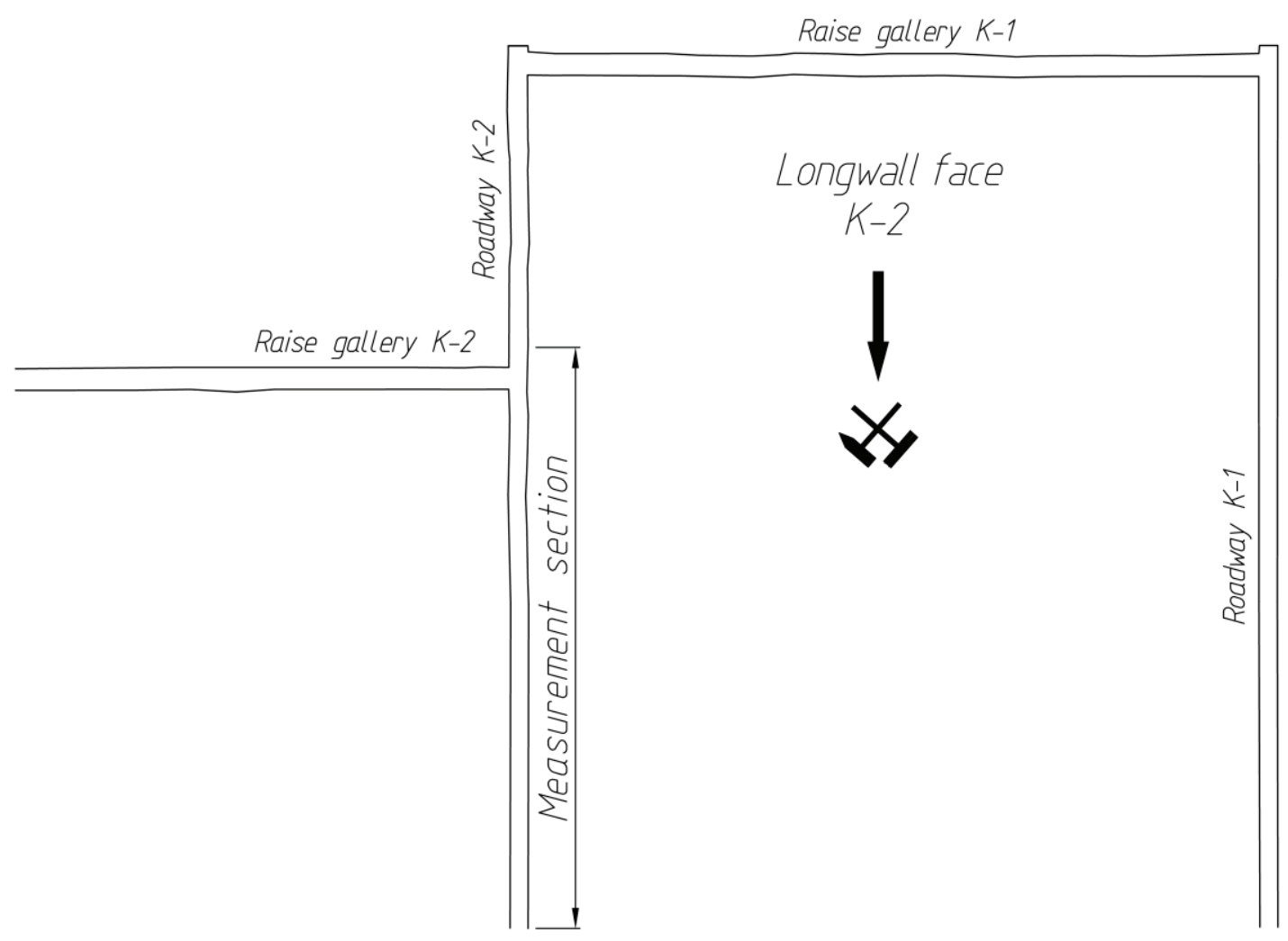

Fig. 1. Site plan of the bottom gate K-2 with marked measurement section 

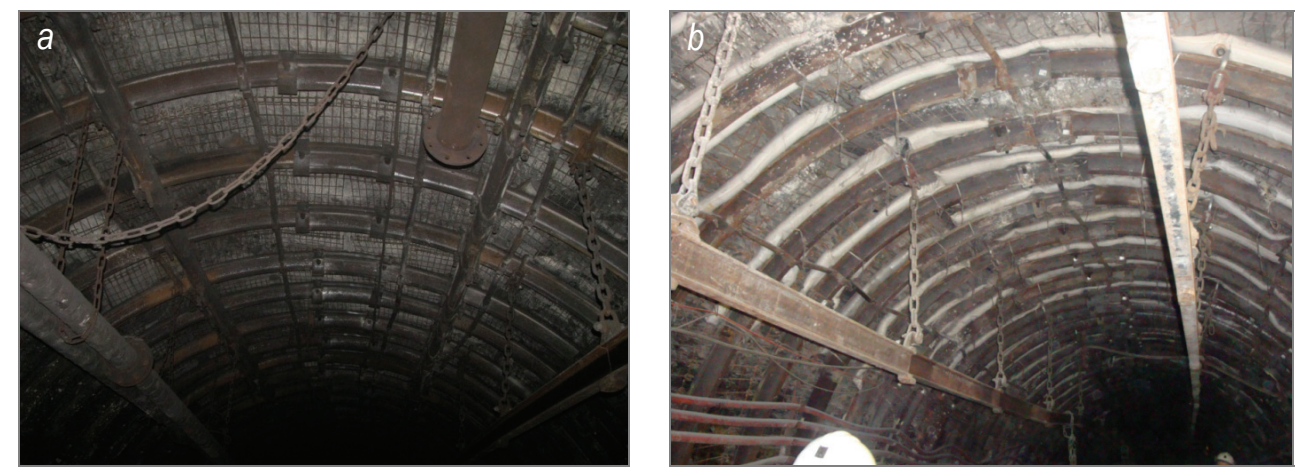

Fig. 2. Support of the bottom gate K-2: (a) support with mechanical lining, (b) support with traditional lining

The inclination of the seam ranges between $3^{\circ}$ and $6^{\circ}$ in North-Eastern direction, locally reaching $8^{\circ}$. The thickness of the seam ranges between $1.2 \mathrm{~m}$ and $3.0 \mathrm{~m}$, including interlayers. In the final longwall panel, the thickness of the seam 362/1 decreases [7].

The existing conditions allowed for the measurements in the part of the roadway with the mechanical lining, as well as in the part without the mechanical lining alongside with the front advance.

The measuring equipment was the FARO 3D laser scanner (Fig. 3).

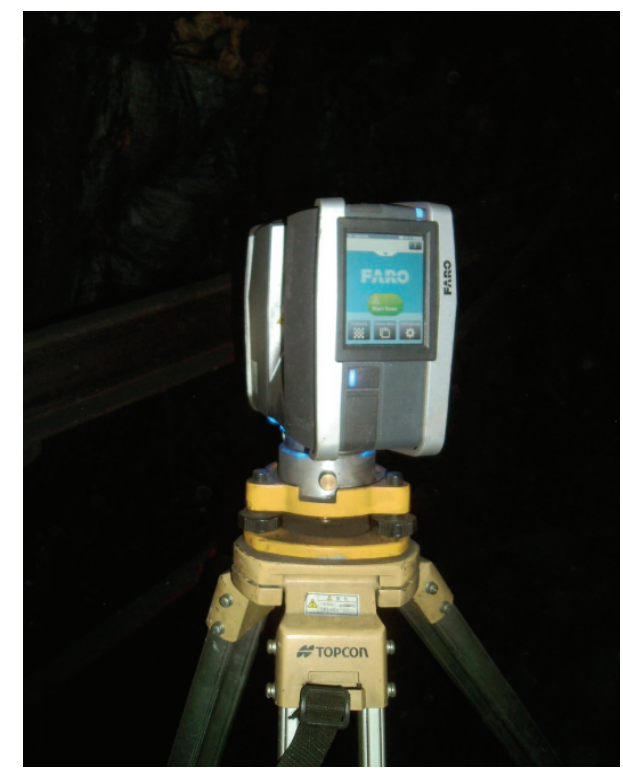

Fig. 3. The FARO Focus 3D scanner during operation

\section{MEASUREMENT PROCEDURE}

The measurement embraced placing at least 3 reference balls in the space before and after the scanner site. The balls were fixed on the support, sidewalls or elements of roadway equipment at a distance of maximum $20 \mathrm{~m}$. Matching the images from particular stations was carried out by means of dedicated professional software. Spatial relations of the centers of at least three balls scanned from the two neighboring stations allow for an automatic matching of individual point clouds. It is the most effective measuring method. As a rule, the precision of terrain point representation decreases alongside with the increasing distance from the scanner. In the tested technology, however, at the "medium" rate of scan resolution for the maximum distance from the scanner, i.e., $20 \mathrm{~m}$, the scanning network was $20 \mathrm{~mm} \times 20 \mathrm{~mm}$. Such a precision, according to the authors, seems absolutely satisfactory for obtaining reliable results of scanning and, at the same time, it is optimal for further data processing.

\section{RESULTS AND ANALYSIS POTENTIAL}

The transfer and analysis of the recorded point clouds with the corresponding matching points (measured tachymetrically) was executed with the use of specialist software, which helps create the set of stations and provide them with geo-reference by means of downloading the text files with coordinates $(x, y, z)$ of the matching points. This method allows for a preparation and matching of the point cloud oriented in a particular system of coordinates. The software manages the scanning data and processes them using automatic object recognition, as well as registering and positioning of scans.

A very important feature is the possibility to deploy scans without the use of targets thanks to the function of an automatic identification. Also the function of filtering the so-called "lost points" seems to be noticeably useful. 
The software also offers the binary data transfer into various commonly applied formats. The spatial model presented below is a result of matching data from 20 stations of the scanner, where the total volume of data reached approx. 1.5 million points. Although unfavorable exposure of the roadway's surface

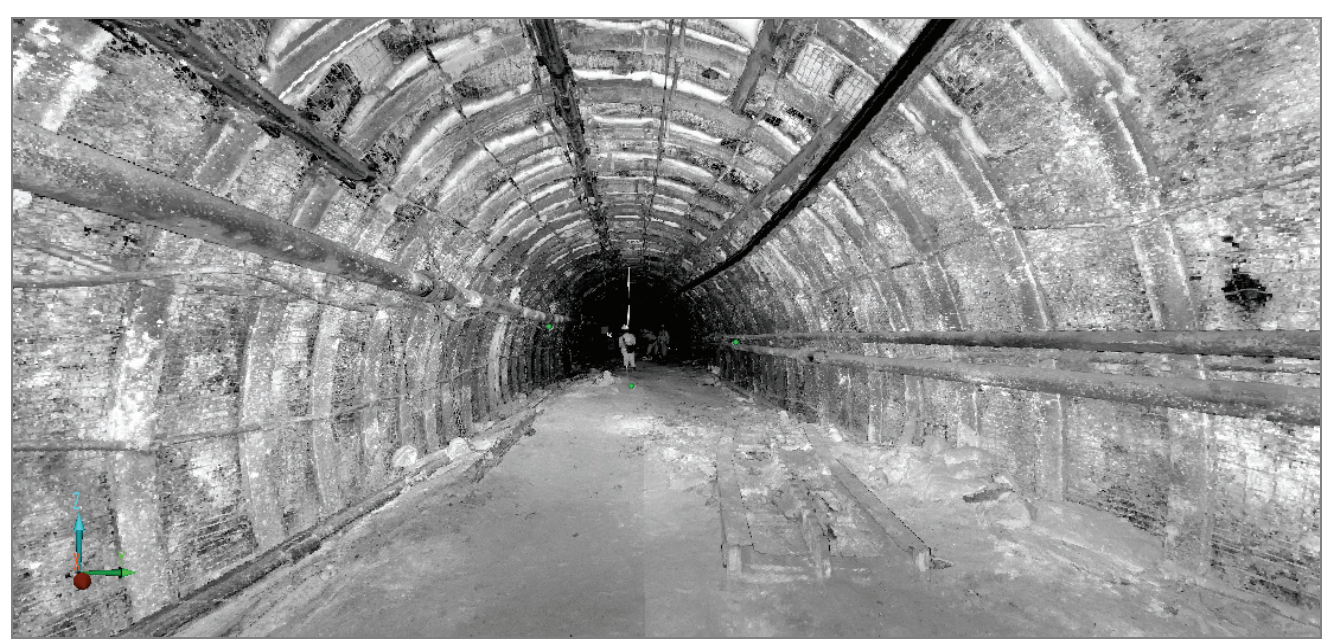

Fig. 4. Representation of details in a single scan
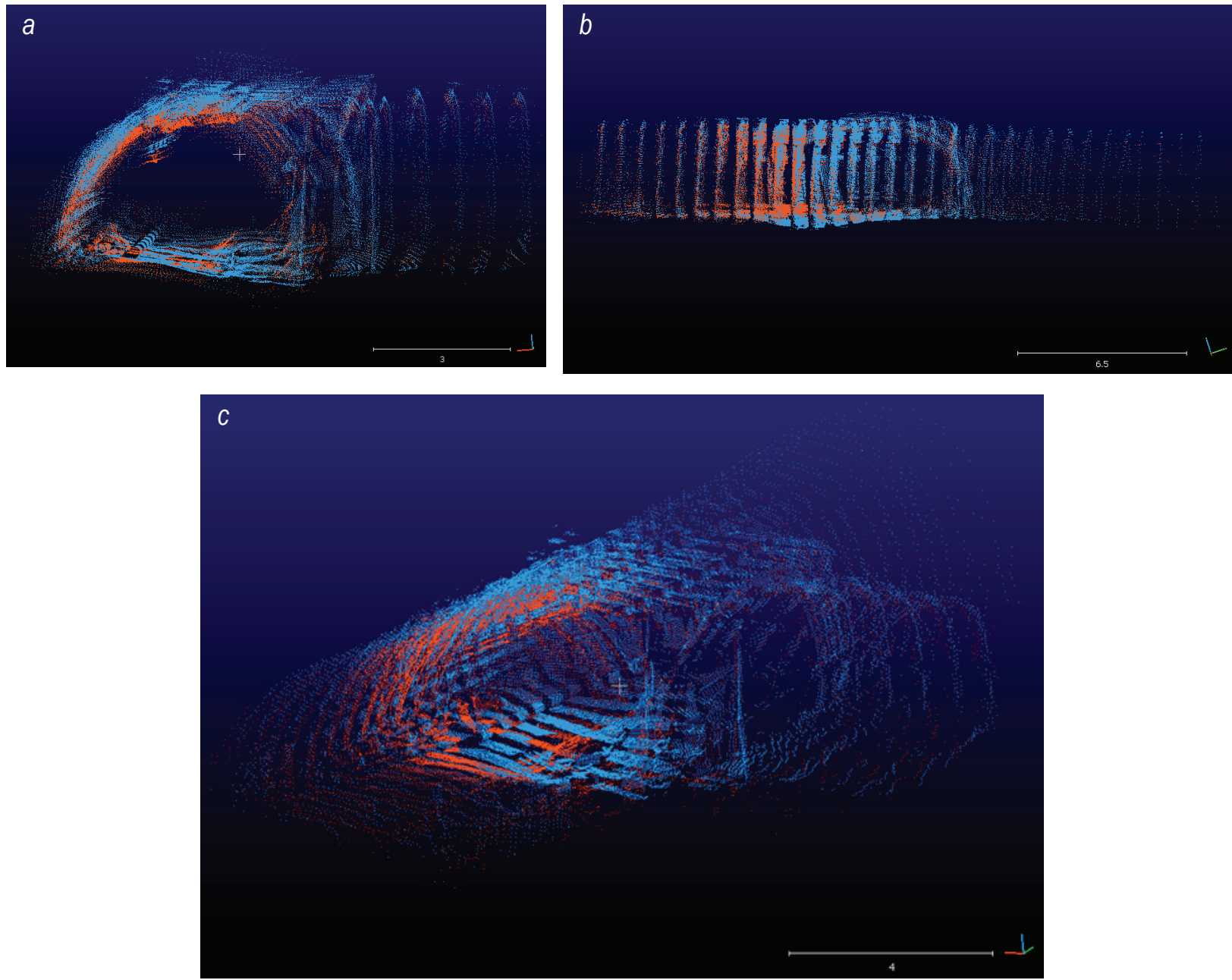

Fig. 5. The view of crossing of the roadway K-2 with the raise gallery K-2

after overlapping two images from two consecutive scanning sessions: (a) the view in the direction of the crossing with the inclined drift $\mathrm{K}-2$, (b) the view from the crossing with the longwall gate $\mathrm{K}-1$,

(c) the isometric view of the crossing of the roadway K-2 with the raise gallery $\mathrm{K}-2$ 
to the laser beam, combined with a relatively low reflectance coefficient, resulted in further reduction of measurement accuracy of the terrain details, such a negative effect, however, was partly balanced by overlapping images obtained from two or more neighboring stations. A fragment of the scanned section is presented in Fig. 4.

The method of determining dislocation in the roadway was based on the analysis of point clouds obtained from 3D scanning.

Figures $5 \mathrm{a}, \mathrm{b}$ and $\mathrm{c}$ present the obtained image after overlapping the data from the consecutive scanning in the bottom gate K-2. The red color represents the second scan made 30 days after the date of the representative scanning. The figures show the change of the cross section of the roadway after the face approached the crossing with the raise gallery K-2 a the distance of 5 meters.

Figure 6 presents the change of dimensions and surface of the cross section determined with the use of scanning results. The black line indicates the shape and dimensions of support before the mining of the wall, whereas the red line shows the shape of support's cross section as the face was approaching the crossing with the raise gallery K-2 to the distance of $5 \mathrm{~m}$. The impact of pressure on the support can be clearly seen as the face approaches the measurement site. The cross section of the support in this place decreased by $1.7 \mathrm{~m}^{2}$, which constituted approx. $12 \%$ of the initial surface of the cross section.

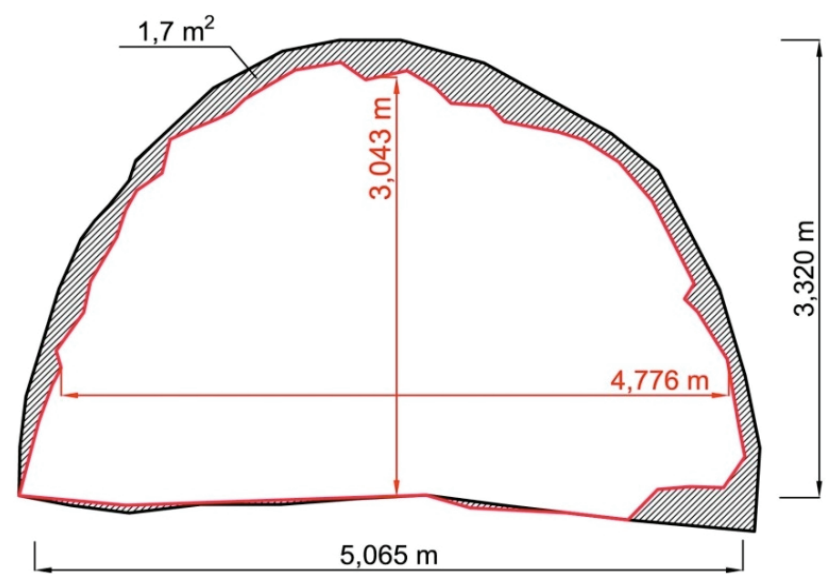

Fig. 6. Changes of dimensions and surface of the cross section of the roadway determined with the use of a 3D scanning

Decreasing the cross section of the roadway by $12 \%$ in the period of 30 days from the date of the previous measurement indicates the irregular influence of the face advance on the behavior of the working before the wall. The observed changes of the cross sec-

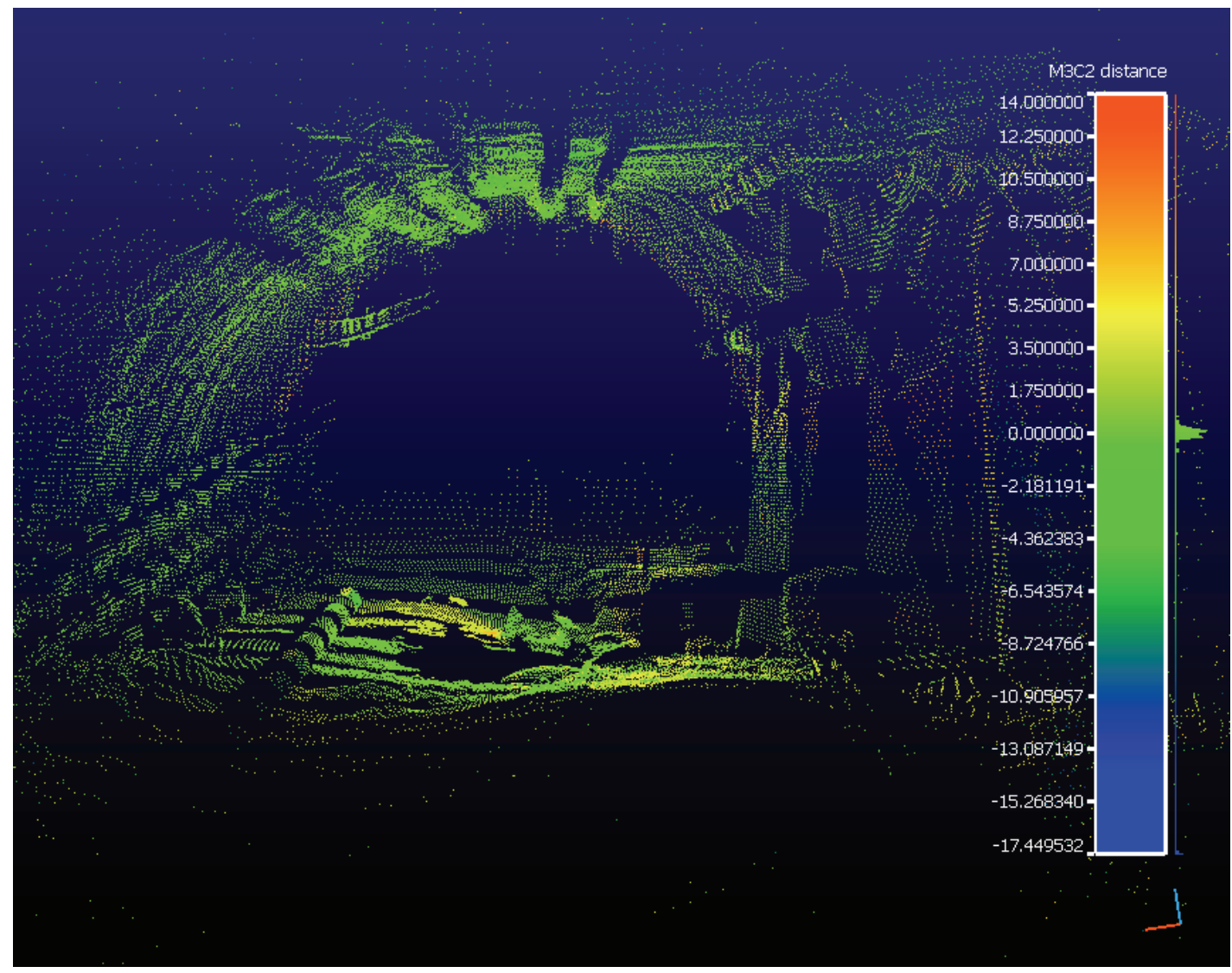

Fig. 7. Image of the roadway fragment after using $\mathrm{M} 3 \mathrm{C} 2$ algorithm (dimensions in $\mathrm{cm}$ ) 
tion of roadways in the direct neighborhood of the face are usually much larger and may reach as much as $40 \%$ of the initial cross section of the roadway [8], [9]. Hence, it may be assumed that in the analyzed case the roadway directly before the front fully preserves its stability.

The application of $\mathrm{M} 3 \mathrm{C} 2$ algorithm (Multiscale Model to Model Cloud Comparsion) allowed for the determination of the distances between point clouds or absolute distances [4]. The dislocations occurring in the bottom gate K-2 in the period of 30 days from the date of making the initial measurement ranged between 0 and $14 \mathrm{~cm}$.

Figure 7 presents the results of measuring the dimensions of the support in the bottom gate K-2 near the crossing with the raise gallery K-2 using $\mathrm{M} 3 \mathrm{C} 2$ algorithm. The image obtained by means of overlapping two point clouds from both scanning sessions allowed for the estimation of changes in the bottom gate K-2 in the selected fragment. The fragment selected for the analysis embraces the crossing of the bottom gate $\mathrm{K}-2$ with the raise gallery K-2.

It should be pointed out here that the closer the crossing with the wall, the higher the values of dislocation. The analysis of the data gathered indicates that after 30 days from the date of the first scanning, primarily the roof and the sidewalls were subject to deformation, whereas the floor in this place and time only deformed slightly (max. $4 \mathrm{~cm}$ ). Figure 7 presents the points which found their representation in the cloud no. 2. The points which failed to be represented in cloud no. 1 were skipped here.

The application of a 3D scanner allows the researchers to determine the changes of the roadway dimensions in time and indicate the changes of its cross section in relation to the standard measurements of convergence. Such a solution is of high significance, particularly due to the possibility of controlling the rate of convergence of the longwall gate roads in relation to the face advance.

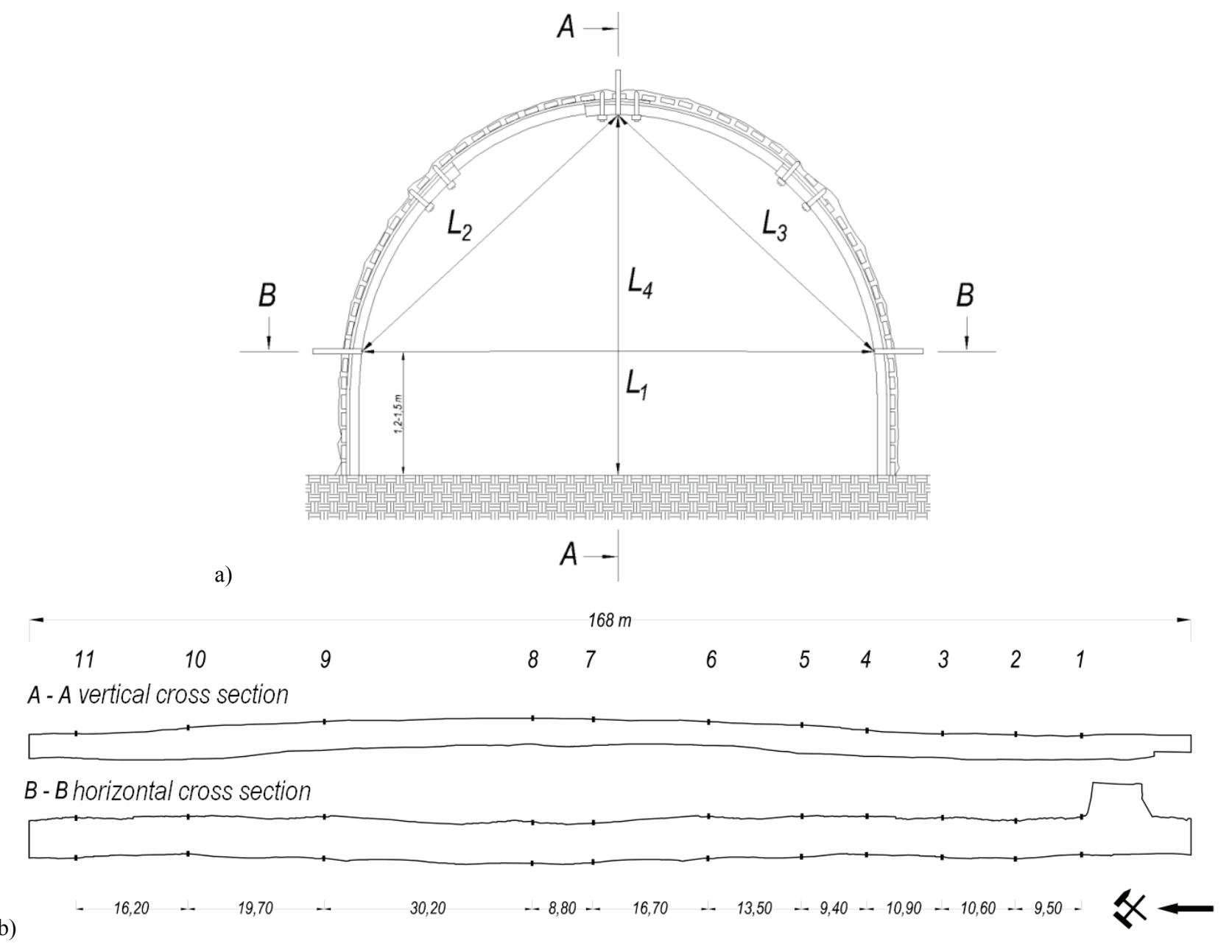

Fig. 8. Convergence measurements in the bottom gate K-2 using a distance meter:

(a) scheme of benchmark distribution for convergence measurement, (b) actual profile of the roadway: A-A vertical cross section (roadway height), B-B horizontal cross section (roadway width) 
In the bottom gate $\mathrm{K}-2$, also standard measurements of convergence were carried out parallel to the measurements with a laser scanning. The convergence tests in the measurement station were carried out on the basis of 4 different measurements embracing: change of the roadway height $\mathrm{L}_{1}$, change of the roadway width $\mathrm{L}_{4}$ and changes of length of the sections in the roadway perimeter $\mathrm{L}_{2}$ and $\mathrm{L}_{3}$ (Fig. 8a). The measurements of convergence in the section of the roadway embracing 168 meters from the crossing with the raise gallery K-2 were carried out in 11 measurement stations situated at $108.2 \mathrm{~m}, 118.7 \mathrm{~m}, 128.8 \mathrm{~m}, 139.7 \mathrm{~m}$, $149.1 \mathrm{~m}, 162.6 \mathrm{~m}, 179.3 \mathrm{~m}, 188.1 \mathrm{~m}, 218.3 \mathrm{~m}, 238 \mathrm{~m}$ and $254.2 \mathrm{~m}$, respectively (Fig. 8b). The first measurements were carried out on May 14, 2014 and they were continued with the frequency of two times per month. The results indicate that in particular cross sections there appeared significant differences of the roadway height and width, reaching as much as almost one meter in the case of width and exceeding one meter in the case of height. The above indicates the occurrence of irregular changes in the roadway already before the commencement of mining.

Table 1 presents a comparison of the results of measurements carried out with the use of a distance meter and with the use of a laser scanning. The differences obtained from the measurements of the roadway height and width using two diverse methods generated different results, however the difference between the horizontal and vertical convergence did not exceed $44 \mathrm{~mm}$, depending on the measurement method. Only at $149.1 \mathrm{~m}$ of the roadway did the difference reach $100 \mathrm{~mm}$. The tests indicate that the measurements carried out with a laser scanner proved more precise.

The analysis of absolute changes of the transverse dimensions of the analyzed roadway indicated that slightly higher values of changes were obtained in the case of the measurements with the use of a distance meter; for vertical convergence they reached a maximum of $136 \mathrm{~mm}$ (Fig. 8a). The measurement with

Table 1. Changes in height and width of the roadway K-2 in the period 14.05.2014-27.06.2014 on the basis of measurement with a distance meter and laser scanning

\begin{tabular}{|c|c|c|c|c|c|}
\hline \multirow{2}{*}{ No. } & $\begin{array}{c}\text { Measuring feature } \\
\text { (measured from the } \\
\text { entrance to the raise } \\
\text { gallery K-2) }[\mathrm{m}]\end{array}$ & $\begin{array}{c}\text { Absolute changes } \\
\text { Period: 14.05.14-27.06.14 } \\
\text { Measurement results from } \\
\text { a distance meter [mm] }\end{array}$ & \multicolumn{2}{|c|}{$\begin{array}{c}\text { Absolute changes } \\
\text { Period: 14.05.14-27.06.14 } \\
\text { Measurement results from } \\
\text { the laser scanning [mm] }\end{array}$} \\
\cline { 3 - 7 } & $\Delta S_{D}[\mathrm{~mm}]$ & $\Delta H_{D}[\mathrm{~mm}]$ & $\Delta S_{L}[\mathrm{~mm}]$ & $\Delta H_{L}[\mathrm{~mm}]$ \\
\hline 1 & 108.70 & 16 & 15 & 7 & 9 \\
\hline 2 & 118.20 & 24 & 31 & 14 & 16 \\
\hline 3 & 128.80 & 96 & 105 & 81 & 77 \\
\hline 4 & 139.70 & 23 & 29 & 11 & 4 \\
\hline 5 & 149.10 & 104 & 136 & 61 & 36 \\
\hline 6 & 162.60 & 62 & 98 & 42 & 54 \\
\hline 7 & 179.30 & 78 & 112 & 65 & 91 \\
\hline 8 & 188.10 & 99 & 43 & 90 & 12 \\
\hline 9 & 218.30 & 24 & 67 & 13 & 52 \\
\hline 10 & 238.00 & 47 & 16 & 39 & 7 \\
\hline 11 & 254.20 & 21 & 29 & 11 & 10 \\
\hline
\end{tabular}
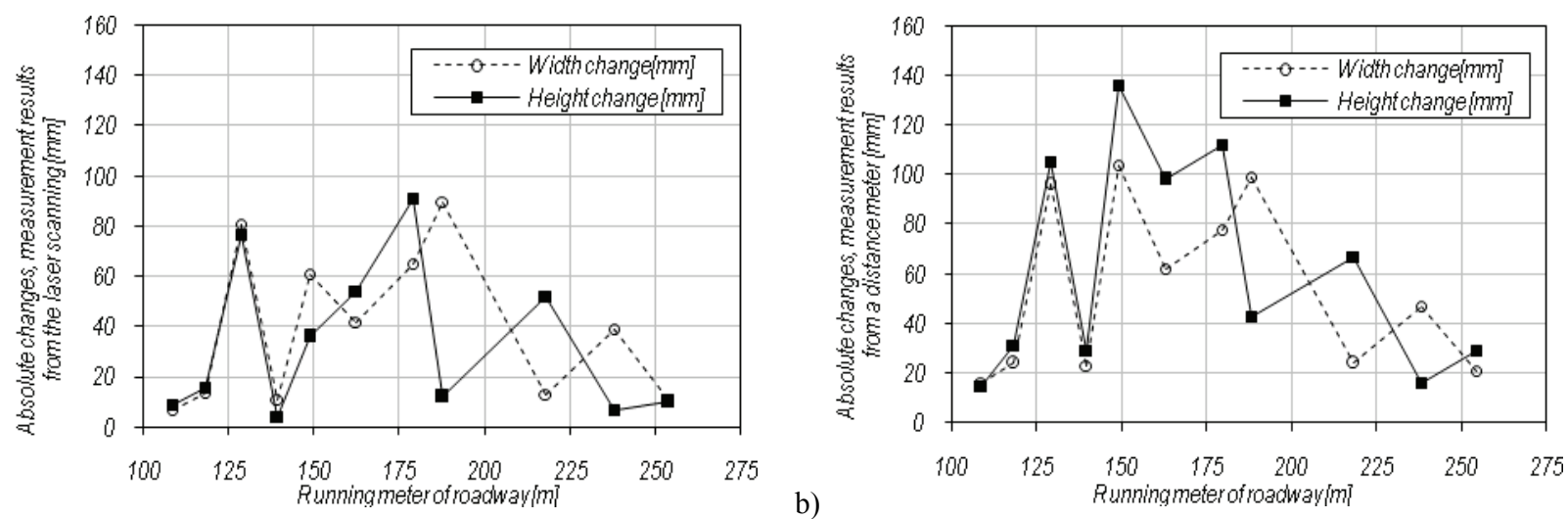

Fig. 9. Difference in absolute changes of height and width of the roadway between the measurements: (a) with the use of a laser scanning, (b) with the use of a distance meter 
a laser scanner at the same station indicated the maximum vertical convergence at $61 \mathrm{~mm}$. The research also showed that in the initial measurement section, where the first measurement base was situated $5 \mathrm{~m}$ away from the face, the changes of convergence were regular, i.e., the change in height and width assumed approximately similar values, independent of the assumed measurement method. In the remaining section, i.e., from the fourth measuring base, the measurement results of horizontal and vertical convergence in the same cross section are different.

The results of measurements generally indicate that despite a relatively small distance from the approaching face, the registered changes are insignificant and do not exceed a dozen of centimeters, depending upon the assumed research method. This clearly indicates that a complete stability of the roadway is preserved both before the face and in the further longwall panel.

A multitude of laser scanning results obtained in the form of the clouds of points in a 3D space allows for creating practically any desired cross sections representing the existing conditions with a high degree of precision. After comparing the consecutive results, the researchers can obtain very detailed information on the course of changes with time. The measurements carried out with the use of a distance meter, based on 44 measuring points, constitute only a tiny fraction of data (i.e., $0.0047 \%$ ) that can be gathered from the 3D laser scanning (930,000 measuring points). Hence, the data obtained from the laser scanning can serve not only for a current estimation of roadway stability but also for anticipating a future design of support reinforcement in its longwall panel. Additionally, after a proper processing the data can be utilized in constructing a mesh of a numerical model and used in the so-called back analysis.

\section{CONCLUSIONS}

The application of a laser scanning offers enormous potential in the measurement of mining excavations. A large number of gathered results allows one to generate a detailed representation of an analyzed object. Largely expanded dedicated software makes it easy to process data from the images of scanning. A 3D scanning is successfully applied in various branches of industry. Applying this technology in mining can be treated as innovative, especially if the analysis embraces the changes of longwall gates with various types of support and different types of lining applied. Standard measurements of roadway convergence may last even dozens of hours, whereas in the case of applying a laser scanner, the total time of tests can be limited to barely a few hours with far less staff engaged in executing measurements.

The results of the research study discussed above prove that the value of contour convergence of the analyzed roadway directly before the face is insignificant, since the displacement of the contour did not exceed $15 \mathrm{~cm}$ and its cross section decreased by approx. $12 \%$. Therefore, it can be argued that at a distance of $5 \mathrm{~m}$ from the face, the roadway shows complete stability. This, in turn, proves that in this particular case, the application of a standard reinforcement of support $10 \mathrm{~m}$ before the face is absolutely satisfactory.

\section{ACKNOWLEDGEMENT}

The project was financed with research grant: AGH No. 11.11.100.277/TM.

\section{REFERENCES}

[1] Armesto J., OrdóÑez C., Alejano L., Arias P., Terrestrial laser scanning used to determine the geometry of a granite boulder for stability analysis purposes, Geomorphology, 2009, 106, 271-277.

[2] EM 1110-1-1005, Control and Topographic Surveying, US Army Corps of Engineers, Engineering and Design, 2005.

[3] Graeve J., Smith J., History of Surveying and Measurement, FIG publication No. 50, 2010.

[4] Lague D., Brodu N., Leroux J., Accurate 3D comparison of complex topography with terrestrial laser scanner: Application to the Rangitikei canyon, (N-Z), ISPRS Journal of Photogrammetry and Remote Sensing, 2013, 82, 10-26.

[5] LIPECKI T., Laser scanning in measurements of geometry and deformation of mining objects and arrangements, Przegląd Górniczy, 2010, No. 7/2010, 25-31, (in Polish).

[6] Maciaszek J., Madusiok D., MatwiJ W., The comparison of the results of laser scanning and classical surveying methods of measuring the area and volume in the chapel of St. Kinga in the salt mine of Bochnia, Geology, Geophysics \& Environment, Akademia Górniczo-Hutnicza im. Stanisława Staszica w Krakowie, 2013, Vol. 39, No. 3, 211-221.

[7] MajcherczyK T., Niedbalski Z., Ulaszek A., Analysis of the co-operation conditions of the roadway's support with the rockmass depending on the parameters of the lining, Wiadomości Górnicze, 2014, 5/2014, 270-276, (in Polish).

[8] MajcherczyK T., OlechowsKi S., Longwall excavation reinforcement in the zones of intensive support deformation, Bezpieczeństwo Pracy i Ochrona Środowiska w Górnictwie, 2009, No. 10, 8-14, (in Polish).

[9] PRUSEK S., Empirical-statistical model of gate roads deformation, Archives of Mining Sciences, 2010, Vol. 55, No. 2, 295-312. 